\title{
PERFORMANCE EVALUATION OF EXTERNAL MIXTURE FORMATION STRATEGY IN HYDROGEN-FUELED ENGINE
}

\author{
Mohammed Kamil ${ }^{1}$, M. M. Rahman ${ }^{2}$ and Rosli A. Bakar ${ }^{2}$ \\ ${ }^{1}$ Department of Mechanical Engineering \\ College of Engineering, University of Tikrit, Tikrit, Iraq \\ E-mail: mohammedk_22@yahoo.com \\ ${ }^{2}$ Faculty of Mechanical Engineering, Universiti Malaysia Pahang \\ 26300 Pekan Campus, Kuantan, Pahang, Malaysia; \\ Phone: +6017-3285990, Fax: +609-87654321
}

\begin{abstract}
Hydrogen induction strategy in an internal combustion engine plays a vital role in increasing the power density and prohibiting combustion anomalies. This paper inspects the performance characteristics of cylinder hydrogen-fueled engine with port injection feeding strategy. To that end, a one-dimensional gas dynamic model has been built to represent the flow and heat transfer in the components of the engine. The governing equations are introduced followed by the performance parameters and model description. Air-fuel ratio was varied from a stoichiometric limit to a lean limit. The rotational speed of the engine was also changed from 1000 to 4500 RPM. The injector location was fixed in the mid-point of the intake port. The general behavior of the hydrogen engine was similar to that of a gasoline engine, apart from a reduction in the power density, which was due to a decrease in the volumetric efficiency. This emphasizes the ability of retrofitting traditional engines for hydrogen fuel with minor modifications. The decrease in the volumetric efficiency needs to be rectified.
\end{abstract}

Keywords: Hydrogen fuel; port injection; feeding strategy; air-fuel ratio; engine speed; gasoline engine.

\section{INTRODUCTION}

Recently, two issues have become of prime importance regarding fuels: availability, and global climate change. The status of the availability of fossil fuels is critical and prices have jumped to levels that never been reached before. Furthermore, environmental problems are serious and severe conditions are being imposed on the automotive industry throughout the world. Researchers, technologists, and automobile manufacturers have been increasing their efforts towards the implementation of technologies that could replace fossil fuels as a means of fueling existing vehicles. Hydrogen, as an alternative fuel, has unique properties that give it significant advantages over other types of fuel. However, widespread implementation of hydrogen for vehicular applications requires several obstacles to be overcome. These obstacles are in the areas of production, transportation, storage, and utilization of hydrogen, of which the latter is the most important. Hydrogen induction techniques play a very dominant and sensitive role in determining the performance characteristics of hydrogen-fueled internal combustion engines $\left(\mathrm{H}_{2} \mathrm{ICEs}\right.$ ) (Suwan, 2003). In general, the hydrogen fuel delivery system can be broken down into three main types: central injection (or 
"carbureted"), port injection, and direct injection (COD, 2001). A comparison between these systems is beyond the present study.

The port injection (PI) fuel delivery system injects hydrogen directly into the intake port, rather than drawing fuel in at a central point. Typically, hydrogen is injected into the port after the beginning of the intake stroke (COD, 2001). Hydrogen can be introduced into the intake port either by continuous or timed injection. The former method produces undesirable combustion problems, is less flexible, and is uncontrollable (Das, 1990). However, the latter method, timed PI, is a strong candidate and extensive studies have indicated the suitability of its adoption (Das, Gulati \& Gupta, 2000; Das, 2002; Tang, Kabat, Natkin, Stockhausen \& Heffel, 2002). The drive for the adoption of this technique is supported by a considerable set of advantages. It can be installed easily with only simple modification required (Lee, Yi \& Kim, 1995) and the cost is low (Li \& Karim, 2006). The flow rate of supplied hydrogen can also be controlled conveniently (Sierens \& Verhelst, 2001). External mixture formation by means of port fuel injection has also been demonstrated to result in higher engine efficiencies, extended lean operation, lower cyclic variation, and lower $\mathrm{NO}_{\mathrm{x}}$ production (Yi, Min \& Kim, 2000; Rottengruber, Berckmüller, Elsässer, Brehm. \& Schwarz, 2004; Kim, Lee \& Caton, 2006). This is the consequence of the higher mixture homogeneity due to longer mixing times for PI. Furthermore, external mixture formation provides a greater degree of freedom concerning storage methods (Verhelst, Sierens \& Verstraeten, 2006).

The most serious problem with PI is the significant possibility of pre-ignition and backfire, especially with rich mixtures (Kabat \& Heffel, 2002; Ganesh, Subramanian, Balasubramanian, Mallikarjuna, Ramesh \& Sharma, 2008). However, conditions with PI are much less severe and the probability for abnormal combustion is reduced because it imparts a better resistance to backfire (COD, 2001). Combustion anomalies can be suppressed by accurate control of injection timing and by elimination of hot spots on combustion surfaces, as suggested by Lee et al. (1995). Verhelst (2005) recommended very late injection. With PI and a stoichiometric mixture, operational engine loads up to an indicated mean effective pressure (IMEP) of 9 bar can be achieved with optimized injection and valve timing (Meier, Karhler, Stolz, Bloss \& AlGarni, 1994). Knorr, Held, Prümm and Rüdiger (1997) have reported acceptable stoichiometric operation with a bus powered by liquid hydrogen. Their success was achieved by using the following method. First, a stratified charge is formed by timed injection of the hydrogen into the pipes of the intake manifold with a defined prestorage angle. At the beginning of the intake stroke, a rich, non-ignitable mixture passes into the combustion chamber. Then, injection of the hydrogen with a relatively low temperature of $0-10{ }^{\circ} \mathrm{C}$, such that the combustion chamber is cooled by the hydrogen and finally, lowering of the compression ratio to $8: 1$. One of the main conclusions drawn from the experimental study of Ganesh et al. (2008) was the possibility of overcoming the problem of backfire by reducing the injection duration. Sierens and Verhelst (2003) examined four different junctions of the port injection position (fuel line) against the air flow. Based on the results of their computational fluid dynamics model, the junction that gave the highest power output (Y-junction) was different from the junction that gave the highest efficiency (45-deg junction). Finally, a compromise was suggested. 


\section{HYDROGEN ENGINE MODEL}

\section{One-Dimensional Basic Equations}

Engine performance can be studied by analyzing the mass and energy flows between individual engine components, and the heat and work transfers within each component. Simulation of one-dimensional flow involves the solution of the conservation equations: mass, energy, and momentum, in the direction of the mean flow.

Mass conservation is defined as the rate of change in mass within a subsystem, which is equal to the sum of $\dot{m}_{\mathrm{i}}$ and $\dot{m}_{\mathrm{e}}$ from the system $\frac{d m}{d t}$ :

$$
\dot{m}_{\mathrm{sub}}=\sum_{i} \dot{m}-\sum_{e} \dot{m}
$$

where subscript $i$ represents the inlet and subscript $e$ represents the exit. In onedimensional flow, the mass flow rate $\dot{m}$, is defined by:

$$
\dot{m}=\rho A U
$$

where $\rho$ is the density, $A$ is the cross-sectional flow area, and $U$ is the fluid velocity.

Energy conservation, the rate of change of energy in a subsystem, is equal to the sum of the energy transfer of the system. Energy conservation can be written in the following form:

$$
\frac{D E}{D t}=\frac{D W}{D t}+\frac{D Q}{D t}
$$

where $E$ is the energy, $W$ is the work, and $Q$ is the heat. Energy conservation results in:

$$
\overbrace{\frac{d(m e)}{d t}}^{\frac{D E}{D t}}=\overbrace{p \frac{d V}{d t}+\sum_{i} \dot{m}_{l} H-\sum_{e} \dot{m}_{e} H}^{\frac{D W}{D t}}-\overbrace{h_{g} A\left(T_{\text {gas }}-T_{\text {wall }}\right)}^{\frac{D Q}{D t}}
$$

where $e$ is the internal energy, $H$ is the total enthalpy, $h_{g}$ is the heat transfer coefficient, and $T_{\text {gas }}$ and $T_{\text {wall }}$ are the temperature of the gas and the wall, respectively. The heat transfer from the internal fluids to the pipe wall is dependent on the heat transfer coefficient, the predicted fluid temperature, and the internal wall temperature. The heat transfer coefficient, which is calculated at every time step, is a function of fluid velocity, thermo-physical properties, and the wall surface roughness. The internal wall temperature is defined here as input data.

$$
h_{g}=\frac{1}{2} C_{f} \rho U_{e f f} C_{P} \operatorname{Pr}^{-\frac{2}{3}}
$$

In Eq. (5), $C_{f}$ is the friction coefficient, $U_{\text {eff }}$ is the effective speed outside the boundary layer, $C_{P}$ is the specific heat, and $\operatorname{Pr}$ is the Prandtl number.

The friction coefficient is related to the Reynolds number as follows:

$$
R_{e}=\frac{\rho U_{c} L_{c}}{v}
$$


where $\rho$ is the density, $U_{c}$ is the characteristic speed, $L_{c}$ is the characteristic length, and $v$ is the dynamic viscosity. The friction coefficient for smooth walls is given by:

$$
\begin{gathered}
C_{f}=\frac{16}{R e_{D}} \\
C_{f}=\frac{0.08}{R e_{D}^{0.25}}
\end{gathered}
$$

where Eq. (7) is used in the region where $R e_{D}<2000$ and Eq. (8) is used in region where $R e_{D}>4000$ with a linear transitional region in between.

The Prandtl number is:

$$
\operatorname{Pr}=\frac{\eta C_{p}}{\lambda}=\frac{\mu}{a}
$$

where $\lambda$ is the heat conduction coefficient, $\mu$ is the kinematic viscosity, and $a$ is the thermal diffusivity.

In the case where the wall surface is rough and the flow is not laminar, the value of the friction coefficient above is given by Nikuradse's formula (Bos, 2007):

$$
C_{f(\text { rough })}=\frac{0.25}{\left(2 \log _{10}\left(\frac{1 D}{2 h}\right)+1.74\right)^{2}}
$$

where $D$ is the pipe diameter, and $h$ is the roughness height.

Momentum conservation, the net pressure forces and wall shear forces acting on a sub system, are equal to the rate of change of momentum in the system:

$$
\frac{\dot{m}}{d t}=\frac{d p A+\sum_{i} m_{l} u+\sum_{l} \dot{m}_{e} u-4 C_{f} \frac{\dot{\rho} u^{2} d x A}{2}-C_{p}\left(\frac{1}{2} \rho u^{2}\right) A}{d x}
$$

where $u$ is fluid velocity, $D$ is the equivalence diameter, $C_{p l}$ is the pressure loss coefficient, and $d x$ is the element length. In order to obtain the correct pressure loss coefficient, the software uses empirical correlations to account for pipe curvature and surface roughness as:

$$
C_{p l}=\frac{p_{1}-p_{2}}{0.5 \rho u_{1}^{2}}
$$

where $p_{1}$ is the inlet pressure, $p_{2}$ is the outlet pressure, and $u_{1}$ is the inlet velocity.

\section{Engine Performance Parameters}

The brake mean effective pressure $(B M E P)$ can be defined as the ratio of the brake work per cycle $W_{b}$ to the cylinder volume displaced per cycle $V_{d}$ (Heywood, 1988; Pulkrabek, 2004) and is expressed as:

$$
B M E P=\frac{W_{b}}{V_{d}}
$$


This equation can be extended for the present four-stroke engine to:

$$
B M E P=\frac{2 P_{b}}{N V_{d}}
$$

where $P_{b}$ is the brake power, and $N$ is the rotational speed.

Brake efficiency $\eta_{b}$ can be defined as the ratio of the brake power $P_{b}$ to the engine fuel energy (Blair, 1999) as:

$$
\eta_{b}=\frac{P_{b}}{m_{f}(L H V)}
$$

where $\dot{m}_{f}$ is the fuel mass flow rate, and $L H V$ is the lower heating value of hydrogen.

The brake specific fuel consumption $(B S F C)$ represents the fuel flow rate $\dot{m}_{f}$ per unit brake power output $P_{b}$ and can be expressed as (Blair, 1999):

$$
B S F C=\frac{m_{f}}{P_{b}}
$$

The volumetric efficiency $\eta_{v}$ of the engine defines the mass of air supplied through the intake valve during the intake period $m_{a}$, by comparison with a reference mass, which is that mass required to fill perfectly the swept volume under the prevailing atmospheric conditions. This can be expressed as (Blair, 1999):

$$
\eta_{v}=\frac{m_{a}}{\rho_{a i} V_{d}}
$$

where $\rho_{a i}$ is the inlet air density.

\section{Computational Model}

A single-cylinder, four-stroke, port injection hydrogen-fueled engine is modeled using GT-Power. The model is built up from several different parts. Engine parameters are given in Table 1. At this point, it is important to indicate that the intake and exhaust ports of the engine cylinder are modeled geometrically with pipes. Several considerations were made to make this model more realistic. Firstly, an attribute "heat transfer multiplier" is used to account for bends, roughness, and additional surface area and turbulence caused by the valve and stem. Furthermore, the pressure losses in these ports are included in the discharge coefficients calculated for the valves.

The in-cylinder heat transfer is calculated by a formula that emulates closely the classical Woschni correlation. Based on this formula, the heat transfer coefficient $\left(h_{c}\right)$ in $\left(\mathrm{W} / \mathrm{m}^{2} . \mathrm{K}\right)$, can be expressed as (Heywood, 1988):

$$
h_{c}=3.26 B^{-0.2} p^{0.8} T^{-0.55} w^{0.8}
$$

where $B$ is the bore in $(m), p$ is the pressure in $(\mathrm{kPa}), T$ is temperature in $(\mathrm{K})$, and $w$ is the average cylinder gas velocity (mls).

The present model calculates the combustion burn rate $X_{b}$, by using the Wiebe function, which can be expressed as (Ferguson \& Kirkpatrick, 2001): 


$$
X_{b}=1-\exp \left[-a\left(\frac{\theta-\theta_{i}}{\Delta \theta}\right)^{n+1}\right]
$$

where $\theta$ is the crank angle, $\theta_{i}$ is the start of combustion, $\Delta \theta$ is the combustion period, and $a$ and $n$ are adjustable parameters.

Table 1. Hydrogen engine parameters

\begin{tabular}{ll}
\hline Engine Parameter [Unit] & Measure \\
\hline Bore [mm] & 100 \\
Stroke [mm] & 100 \\
Connecting Rod Length [mm] & 220 \\
Piston Pin Offset [mm] & 1.00 \\
Displacement [liter] & 0.785 \\
Compression Ratio & 9.5 \\
IVC [CA] & -96 \\
EVO [CA] & 125 \\
IVO [CA] & 351 \\
EVC [CA] & 398 \\
\hline
\end{tabular}

The injection of hydrogen was located in the mid-point of the intake port. Figure 1 shows the model of the hydrogen single-cylinder engine.

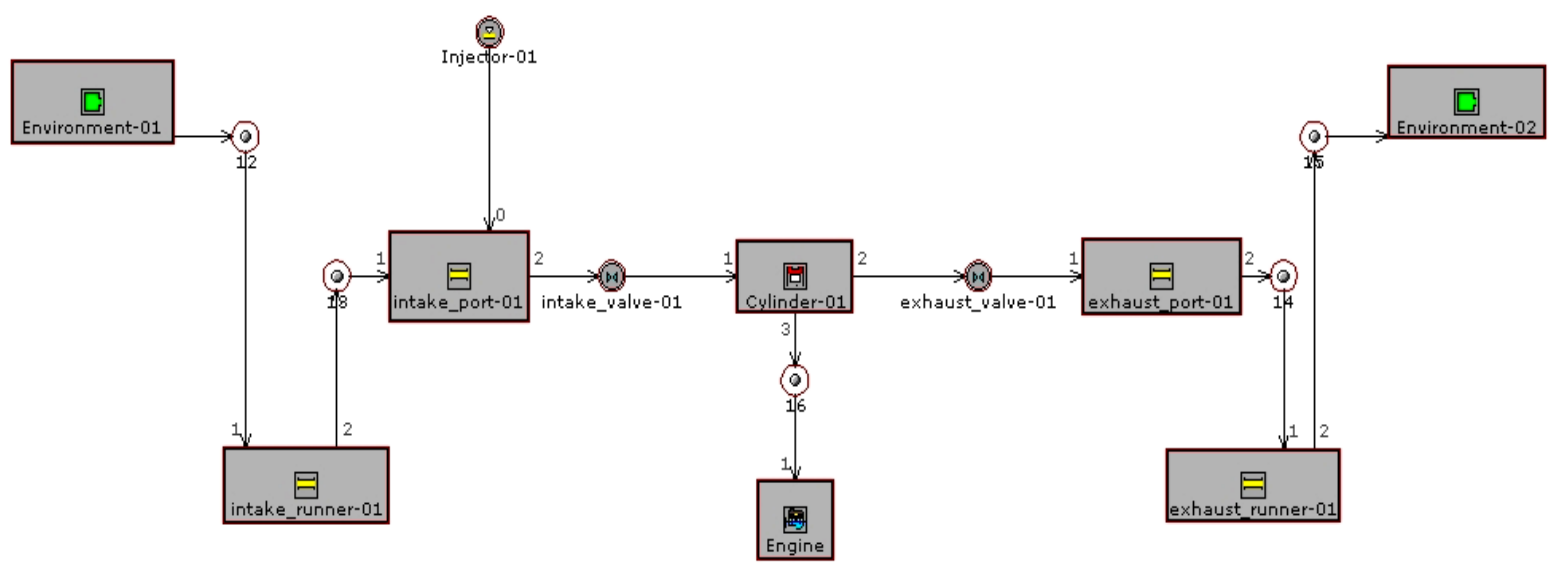

Figure 1. Engine model.

\section{RESULTS AND DISCUSSION}

This section presents the results of the built model. The first subsection presents the results obtained by varying the air-fuel ratio (AFR) and the second part shows the effects of rotational speed.

\section{Tends of Mixture Composition}

It should be noted that one of the most attractive combustive features of hydrogen fuel is its wide range of flammability. A lean mixture is one in which the amount of fuel is 
less than the stoichiometric mixture; this makes it easy to get an engine to start. Furthermore, fuel economy will be greater and the combustion reaction will be more complete. Additionally, the final combustion temperature is lower, thereby reducing the amount of pollutants (COD, 2001). At engine speeds of 2500, 3500, and $4500 \mathrm{RPM}$, the AFR was varied from stoichiometric limits (AFR $=34.33: 1$ based on mass) to a very lean limit (AFR =68.66). Figure 2 shows the BMEP as a function of AFR. BMEP is a good parameter for comparing engines with regard to design because it is independent of both engine size and speed. If torque is used for engine comparison, a large engine will always appear to perform better. If power is used as the comparison, speed becomes very important (Pulkrabek, 2004). It is apparent that BMEP falls nonlinearly from the richest setting where AFR is 43.33, to the leanest setting where the AFR is 65 . Owing to dissociation at high temperatures following combustion, molecular oxygen is present in the burned gases under stoichiometric conditions; therefore, some additional fuel can be added and partially burned. This increases the temperature and the number of moles of the burned gases in the cylinder. These effects increase the pressure and thereby increase the power and mean effective pressure (Heywood, 1988).

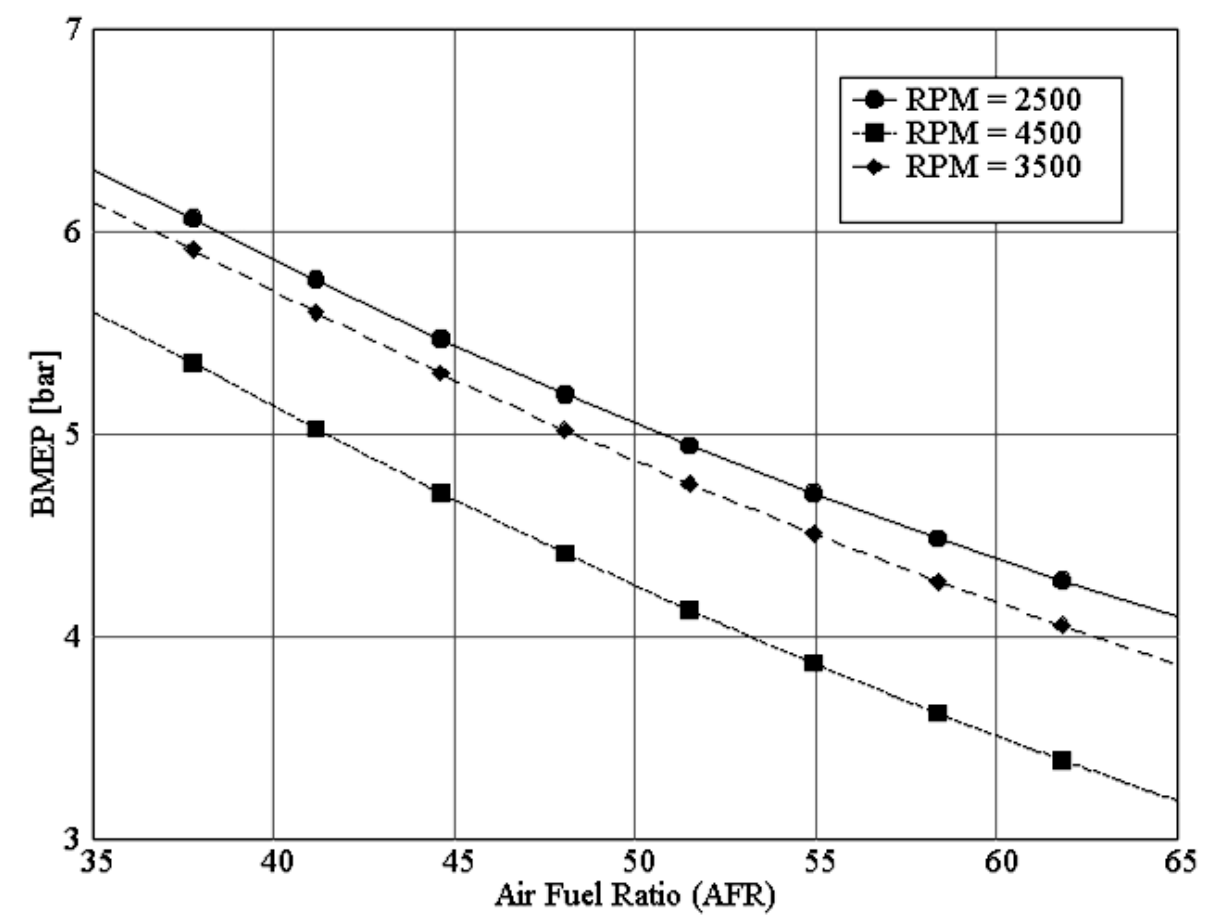

Figure 2. Variation of BMEP vs. AFR.

Figure 3 shows the variation of the brake thermal efficiency with the air-fuel ratio for the selected speeds. It shows the useful part (brake power) as a percentage of the intake fuel energy. The fuel energy covers the friction losses and heat losses (heat loss to surroundings, exhaust enthalpy, and coolant load). Brake efficiency increases to a maximum and then decreases. Rotational speed has a significant effect in the behavior of $\eta_{b}$ with AFR. At low RPM, the variation of $\eta_{b}$ appears slow and a small slope can be seen. Furthermore, the location of the maximum $\eta_{b}$ on the x-axis (AFR axis) is shifted more to the right (i.e., higher AFR). Figure 4 depicts the behavior of the BSFC with AFR. The AFR for optimum fuel consumption at a given load depends on the details of chamber design (including compression ratio) and mixture preparation quality. It also 
varies for a given chamber depending on the throttle load and speed range (Heywood, 1988). Figure 4 shows clearly that at higher speeds, there is higher fuel consumption. This is because greater friction losses occur at higher speeds. Furthermore, it is easy to perceive that the decrease in rotational speed increases the value of AFR, which gives the required minimum AFR. At very lean conditions, higher fuel consumption can be noticed. This is because leaner operation can lead to unstable combustion and more lost power owing to a reduction in the volumetric heating value of the air/hydrogen mixture. This behavior can be seen more clearly by referring to Figure 3, where the brake efficiency is reduced considerably at very lean operating conditions. Figure 5 shows how the AFR can affect the maximum temperature inside the cylinder. In general, lower temperatures are required because it will reduce the amount of pollutants. It is clearly demonstrated how the increase in the AFR decreases the maximum cylinder temperature with a severely steep curve.

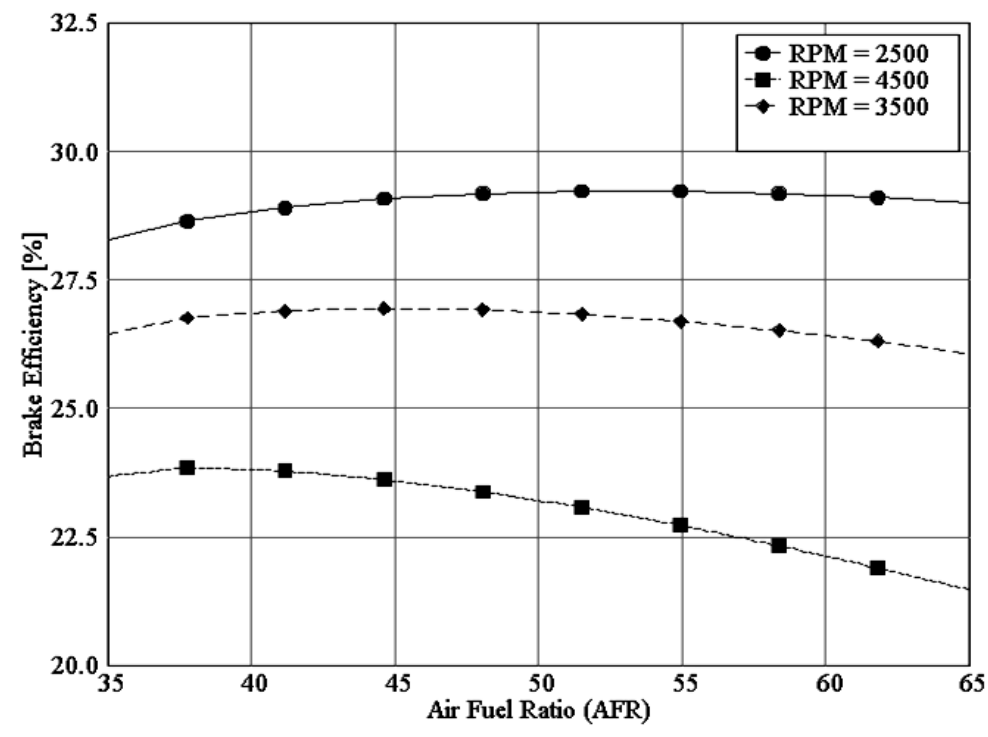

Figure 3. Variation of $\eta_{b}$ vs. AFR.

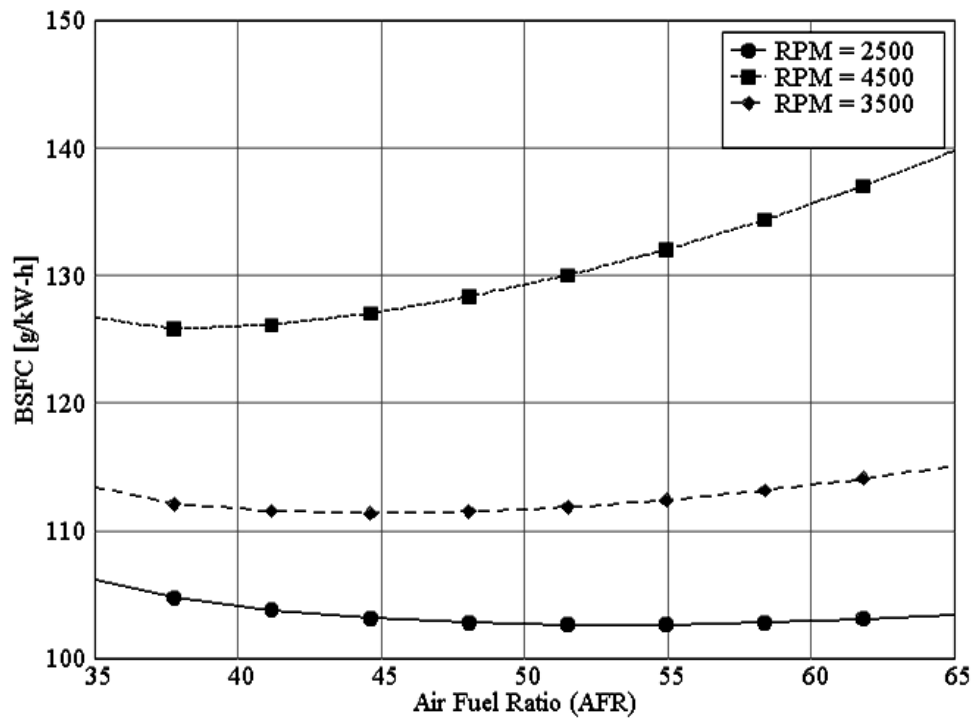

Figure 4. Variation of BSFC vs. AFR. 


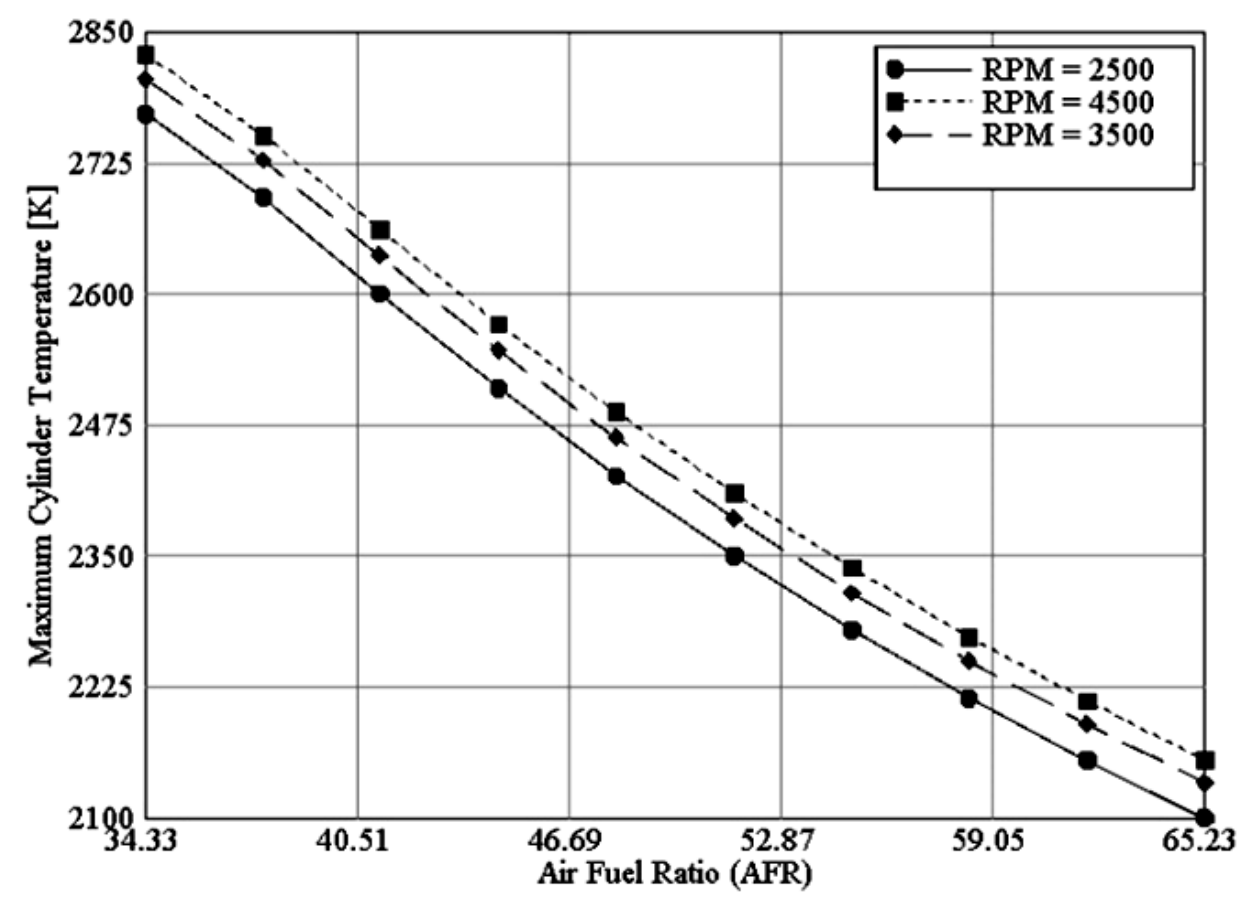

Figure 5. Variation of maximum cylinder temperature vs. AFR.

\section{Trends of Engine Speed}

Figure 6 shows the variation of the volumetric efficiency with the engine rotational speed for stoichiometric operation. In general, it is desirable to have maximum volumetric efficiency for any engine. This importance is more critical for hydrogen engines because the hydrogen gas fuel displaces large amounts of the incoming air owing its low density. This reduces the volumetric efficiency to great extent. For example, a stoichiometric mixture of hydrogen and air consists of approximately $30 \%$ hydrogen by volume, whereas a stoichiometric mixture of fully vaporized gasoline and air consists of approximately $2 \%$ gasoline by volume (White, Steeper \& Lutz, 2006). Therefore, low volumetric efficiency for a hydrogen engine is expected compared with a gasoline engine working with under same operating conditions and physical dimensions. This lower volumetric efficiency is apparent in Figure 6. Many solutions have been suggested to overcome this problem. Nagalingam, Dübel \& Schmillen (1983), Furuhama and Fukuma (1986), and Lynch (1983) suggested and carried out tests with pressure-boosting systems for hydrogen engines. Knorr et al. (1997) suggested using liquid hydrogen instead of gaseous hydrogen to reduce the volume occupied by the fuel. White et al. (2006) suggested direct injection (in-cylinder) for hydrogen. The direct injection topic is beyond the scope of the present paper. Higher speeds lead to higher volumetric efficiency. Higher speeds give higher vacuum at the intake port and consequently, larger amounts of air can be drawn into the cylinder. Leaner mixtures can give higher volumetric efficiency, as shown. 


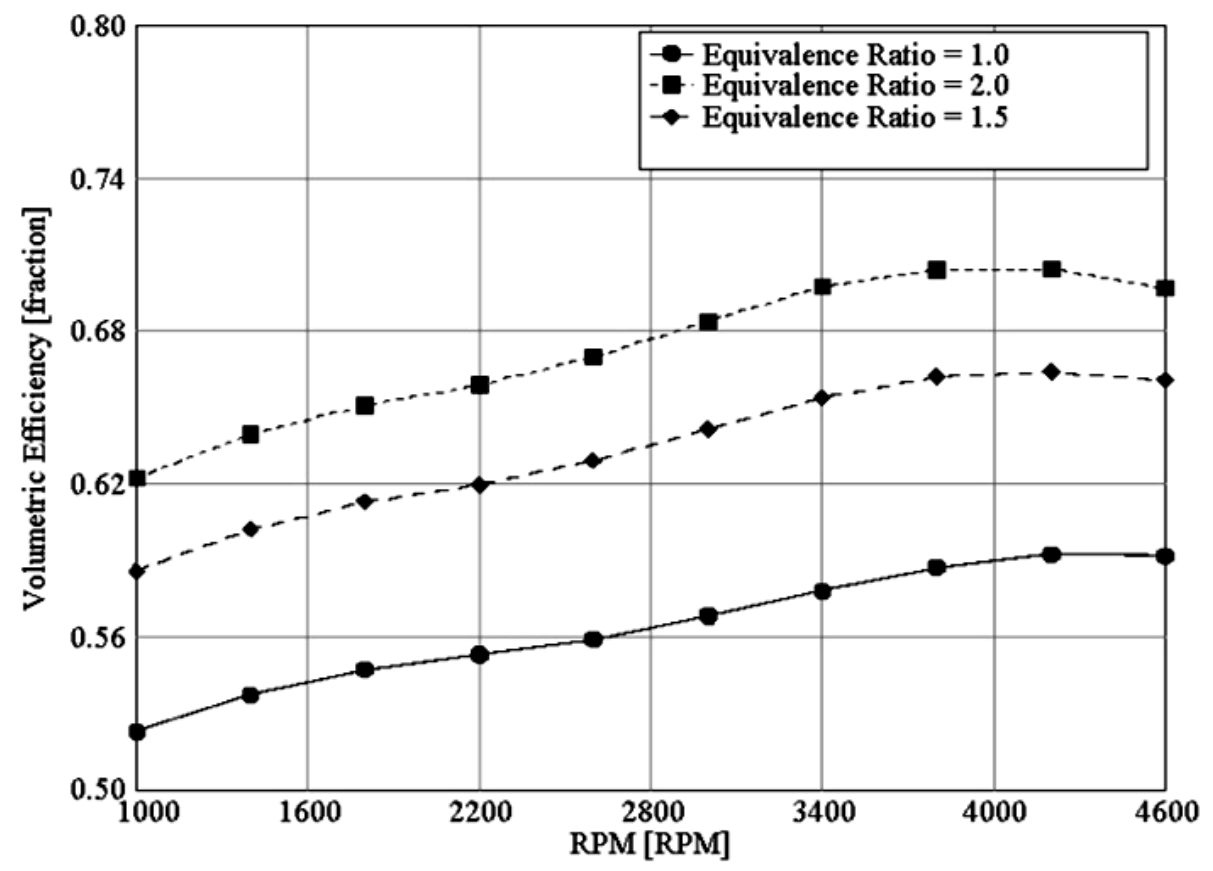

Figure 6. Volumetric efficiency vs. RPM

Figure 7 shows the burn duration as a function of the engine speed for different AFRs. As stated earlier, hydrogen combustion velocity is rapid compared with that of gasoline and therefore, short burn duration is expected. It is well established that the duration of combustion in crank angle degrees only increases slowly with increasing speed (Heywood, 1988). This is apparent from this figure, where the range of combustion duration changes with a value of 0.015 degree within a range of 3600 RPM.

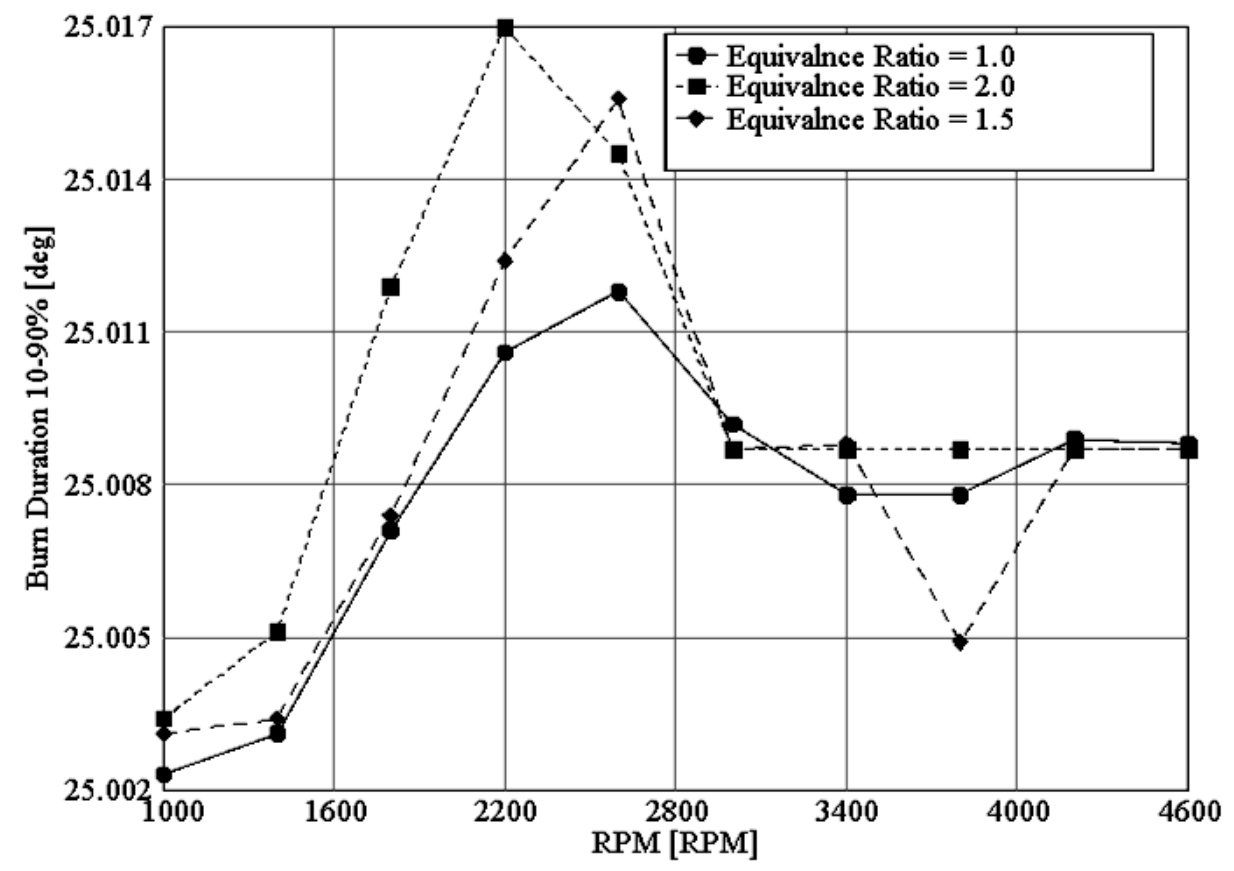

Figure 7. Combustion duration vs. RPM. 


\section{CONCLUSION}

The present study introduced a performance simulation for a single-cylinder hydrogenfueled internal combustion engine with hydrogen being injected into the intake port. In general, the behavior of most of the studied parameters is similar to that of gasoline engines. This offers a significant possibility of retrofitting gasoline engines for hydrogen fuel with only minor or simple modifications. The volumetric efficiency of hydrogen engines with port fuel injection is a serious problem, which reduces the overall performance of the engine. Some solutions should be investigated to overcome this problem, such as pressure boosting. Further experimental work will be done in the future to develop this simulation and obtain further details.

\section{ACKNOWLEDGMENTS}

The authors would like to express their deep gratitude to Universiti Malaysia Pahang (UMP) for providing the laboratory facilities and financial support (RDU100387).

\section{REFERENCES}

Blair, G. P. (1999). Design and simulation of four-stroke engines. Warrandale, Pa.: SAE International. Society of Automotive Engineers Inc.

Bos, M. (2007). Validation Gt-Power model cyclops heavy duty diesel engine. M.Sc. Thesis, Technical University of Eindhoven, UK.

COD (College of the Desert). (2001). Hydrogen fuel cell engines, Module 3: Hydrogen use in internal combustion engines. Revision 0.

Das, L. (1990). Fuel induction techniques for a hydrogen operated engine. International Journal of Hydrogen Energy, 15(11), 833-842.

Das, L. (2002). Hydrogen engine: research and development (R\&D) programmes in Indian Institute of Technology (IIT), Delhi. International Journal of Hydrogen Energy, 27, 953-965.

Das L., Gulati, R., \& Gupta, P. (2000). A comparative evaluation of the performance characteristics of a spark ignition engine using hydrogen and compressed natural gas as alternative fuels. International Journal of Hydrogen Energy, 25, 783-793.

Ferguson, C. R., \& Kirkpatrick, A. T. (2001). International combustion engine. Second edition. New York: John Wiley and Sons, Inc.

Furuhama, S., \& Fukuma, T. (1986). High output power hydrogen engine with high pressure fuel injection, hot surface ignition and turbocharging. International Journal of Hydrogen Energy, 11, 399-407.

Ganesh, R., Subramanian, V., Balasubramanian, V., Mallikarjuna, J., Ramesh, A., \& Sharma, R. P. (2008). Hydrogen fueled spark ignition engine with electronically controlled manifold injection: An experimental study. Renewable Energy, 33, 1324-1333.

Heywood, J. B. (1988). Internal combustion engine fundamentals. New York: McGrawHill.

Kabat, D. M., \& Heffel, J. W. (2002). Durability implications of neat hydrogen under sonic flow conditions on pulse-width modulated injectors. International Journal of Hydrogen Energy, 27, 1093-1102. 
Kim, Y. Y., Lee, J. T., \& Caton, J. A. (2006). The development of a dual-Injection hydrogen-fueled engine with high power and high efficiency. Journal of Engineering for Gas Turbines and Power, ASME, 128, 203-212.

Knorr, H., Held, W., Prümm, W., \& Rüdiger, H. (1997). The MAN hydrogen propulsion system for city buses. International Journal of Hydrogen Energy, 23, 201-208.

Lee, S. J., Yi, H. S., \& Kim, E. S. (1995). Combustion characteristics of intake port injection type hydrogen fueled engine. International Journal of Hydrogen Energy, 20 (4), 317-322.

Li, H., \& Karim, G. A. (2006). Hydrogen fueled spark-ignition engines predictive and experimental performance. Transactions of the ASME, 128, 230-236.

Lynch, F. E. (1983). Parallel induction: a simple fuel control method for hydrogen engines. International Journal of Hydrogen Energy, 8, 721-730.

Meier, F., Karhler, J., Stolz, W., Bloss, W. H., \& Al-Garni, M. (1994). Cycle-resolved hydrogen flame speed measurement with high-speed Schlieren technique in a hydrogen direct injection SI engine. SAE Paper, No. 942036.

Nagalingam, B., Dübel, M., \& Schmillen, K. (1983). Performance of the supercharged spark ignition hydrogen engine. SAE Paper, No. 831688.

Pulkrabek, W. W. (2004). Engineering fundamentals of the internal combustion engines. Second edition. New York: PEARSON Prentic Hall.

Rottengruber, H., Berckmüller, M., Elsässer, G., Brehm, N., \& Schwarz, C. (2004). Direct-injection hydrogen SI-engine operation strategy and power density potentials. SAE Paper, No. 2004-01-2927.

Sierens, R., \& Verhelst, S. (2001). Experimental study of a hydrogen-fueled engine. Journal of Engineering for Gas Turbines and Power, ASME, 123, 211-216.

Sierens, R., \& Verhelst, S. (2003). Influence of the injection parameters on the efficiency and power output of a hydrogen-fueled engine. Trans of ASME, 195, 444-449.

Suwan, N. (2003). Performance of a spark ignition dual-fueled engine using splitinjection timing. Ph.D. Thesis. Vanderbilt University, USA.

Tang, X., Kabat, D. M., Natkin, R. J., Stockhausen, W. F., \& Heffel, J. (2002). Ford P2000 hydrogen engine dynamometer development. SAE Paper, No. 2002-010242.

Verhelst, S. (2005). A study of the combustion in hydrogen-fuelled internal combustion engines. Ph.D. Thesis, Ghent University, Belgium.

Verhelst, S., Sierens, R., \& Verstraeten, S. (2006). A critical review of experimental research on hydrogen fueled SI engines. SAE Paper, No. 2006-01-0430.

White, C. M., Steeper, R. R., \& Lutz, A. E. (2006). The hydrogen-fueled internal combustion engine: a technical review. International Journal of Hydrogen Energy, 31, 1292-1305.

Yi, H. S., Min, K., \& Kim, E. S. (2000). The optimized mixture formation for hydrogen fuelled. International Journal of Hydrogen Energy, 25, 685-690. 